Article

\title{
Silica Pillared Montmorillonites as Possible Adsorbents of Antibiotics from Water Media
}

\author{
Maria Eugenia Roca Jalil 1,2,* , Florencia Toschi ${ }^{1}$, Miria Baschini ${ }^{1,2}$ and Karim Sapag ${ }^{3}$ (iD) \\ 1 PROBIEN (CONICET-UNCo), Buenos Aires 1400, Neuquén 8300, Argentina; \\ florencia.toschi@probien.gob.ar (F.T.); miria.baschini@fain.uncoma.edu.ar (M.B.) \\ 2 Dpto de Qca-Facultad de Ingeniería, Universidad Nacional del Comahue, Buenos Aires, \\ Neuquén 1400, Argentina \\ 3 Laboratorio de Sólidos Porosos, Instituto de Física Aplicada-CONICET, Universidad Nacional de San Luis, \\ Ejército de los Andes 950, Bloque II, 2do piso, San Luis 5700, Argentina; sapag@unsl.edu.ar \\ * Correspondence: eugenia.rocajalil@probien.gob.ar; Tel.: +54-2994490300 (ext. 688)
}

Received: 18 July 2018; Accepted: 16 August 2018; Published: 19 August 2018

Featured Application: Silica pillared clays have not been studied as adsorbents from water media. However, Si-PILC represent an interesting option as selective adsorbents of emerging compounds.

\begin{abstract}
In this work, three silica pillared clays (Si-PILC) were synthetized, characterized, and evaluated as possible adsorbents of ciprofloxacin (CPX) and tetracycline (TC) form alkaline aqueous media. The pillared clays obtained showed significant increases in their specific surface areas $\left(\mathrm{S}_{\mathrm{BET}}\right)$ and micropore volumes $\left(\mathrm{V}_{\mu \mathrm{p}}\right)$ regarding the raw material, resulting in microporosity percentages higher than $57 \%$ in all materials. The studies of CPX and TC removal using pillared clays were compared with the natural clay and showed that the Si-PILC adsorption capacities have a strong relationship with their porous structures. The highest adsorption capacities were obtained for CPX on Si-PILC due to the lower molecular size of CPX respect to the TC molecule, favoring the interaction between the $\mathrm{CPX}^{-}$and the pillars adsorption sites. Tetracycline adsorption on silica pillared clays evidenced that for this molecule the porous structure limits the interaction between the $\mathrm{TCH}^{-}$and the pillars, decreasing their adsorption capacities. However, the results obtained for both antibiotics suggested that their negative species interact with adsorption sites on the pillared structure by adsorption mechanisms that involve inner-sphere complex formation as well as van der Waals interactions. The adsorption mechanism proposed for the anionic species on Si-PILC could be considered mainly as negative cooperative phenomena where firstly there is a hydrophobic effect followed by other interactions, such as der Waals or inner-sphere complex formation.
\end{abstract}

Keywords: silica pillared clays; antibiotics adsorption

\section{Introduction}

The presence of antibiotics in the environment has been widely reported in the last decades and it is a key indicator of the low efficiency of the current effluent treatments in their complete removal. Therefore, several studies have focused on developing techniques to be used as a complement to the actual treatments, allowing the complete removal of this kind of contaminant. Due to the operational simplicity, simple design, and availability of several adsorbents, adsorption is one of the most interesting studies [1-5]. Many adsorbents have been proved to remove antibiotics from water media [6-10]. Among them, clay minerals have low cost and are environmentally compatible materials and, bentonites in particular, have shown to be good adsorbents of many different pharmaceutical 
compounds [11-17]. Nevertheless, the behavior of bentonite suspensions produces some limitations in their separation from the adsorption aqueous medium and a possible solution for this is to modify the natural clay with the aim of increasing its hydrophobicity. From bentonites is possible to synthesize micromesoporous materials with high specific surface areas and permanent porosities regarding raw materials [17]. These materials, named pillared clays (PILC), have shown to be good adsorbents for different organic compounds with the advantage of having higher hydrophobicities than natural clays, which allows for an easier separation of the adsorption media [18-25].

The pillared clays usually studied as adsorbents are aluminum, zirconia, and iron pillared clays. In a previous work, four different PILC were synthetized and evaluated as ciprofloxacin adsorbents from aqueous media [25]. Among them, one silica pillared clay showed to be a good adsorbent of this antibiotic and the results suggest that there exists an interesting relationship between the porous structure of the Si-PILC and its adsorption capacity. Up to now, the silica pillared clays have been used mainly as catalysts but there are no studies about their adsorbent capacities. Therefore, in this work, three silica pillared clays were synthetized and characterized by different techniques with the aim of studying the relationship between their porous structure and their removal capacity for ciprofloxacin and tetracycline from aqueous media.

\section{Materials and Methods}

\subsection{Synthesis and Characterization of Silica Pillared Clays (Si-PILC)}

The raw material used in this work was bentonite (natural clay, NC) from Pellegrini Lake in the province of Rio Negro, Argentina, described in detail in a previous work [16]. The silica pillared clays (Si-PILC) were prepared following the methodology described by Han et al. [26] with some modifications. The silica sol solution used as pillaring agent was obtained by mixing tetraethyl orthosilicate (TEOS: $\mathrm{Si}(\mathrm{OEt})_{4}$, Merck > 99\%), $2 \mathrm{M} \mathrm{HCl}$ (Cicarelli, 36.5-38\%), and ethanol in a molar ratio of 1:0.1:1. The resulting solution was then aged at room temperature and mixed with a $0.25 \mathrm{M}$ ferric nitrate $\left(\mathrm{Fe}\left(\mathrm{NO}_{3}\right)_{3} .9 \mathrm{H}_{2} \mathrm{O}\right.$, Anedra $\left.99 \%\right)$ solution in a molar ratio of $\mathrm{Si} / \mathrm{Fe} 10: 1$. This mixture was titrated with a $0.2 \mathrm{M} \mathrm{NaOH}$ (Anedra, 98\%) solution up to a $\mathrm{pH}$ of 2.7. Then, the pillaring agent obtained was added drop-wise to an NC suspension of $1 \mathrm{wt} \%$ deionized water and, considering its cation exchange capacity (CEC), the molar ratio chosen was Si:Fe:CEC 50:5:1, respectively. During the cation exchange, the mixture was stirred $3 \mathrm{~h}$ at $60^{\circ} \mathrm{C}$ and the solid was separated by centrifugation at $3500 \mathrm{rpm}$ for $15 \mathrm{~min}$ by a Sorvall RC 5C centrifuge. This solid was washed with a solution of ethanol/water $50 \%$ $v / v$ and then was dispersed in a $0.2 \mathrm{M} \mathrm{HCl}$ solution under stirring for $3 \mathrm{~h}$. This last step was carried out four more times. Finally, the solid material was washed with deionized water several times and then dried to finally obtain the Si-pillared clay precursor. Three materials were synthetized by this procedure varying the molar ratio between the $\mathrm{Si}$ and natural clay CEC and obtaining Si-PILC precursors with ratios of 25, 50, and $75 \mathrm{~mol} \mathrm{Si.g}^{-1}$ of natural clay. Finally, the precursors of the Si-PILC were calcined at $500{ }^{\circ} \mathrm{C}$ for $1 \mathrm{~h}$ in order to obtain the Si-PILC 25,50 , and 75, respectively.

The structural properties of the materials were analyzed by X-Ray Diffraction (XRD) and Fourier transform infrared spectroscopy (FTIR). The XRD were obtained using a RIGAKU Geigerflex X-ray diffractometer with $\mathrm{CuK} \alpha$ radiation at $20 \mathrm{~mA}$ and $40 \mathrm{kV}$. The scans were recorded between $2^{\circ}$ and $70^{\circ}$ (20) with a step size of $0.02^{\circ}$ and a scanning speed of $2^{\circ} \mathrm{min}^{-1}$. The FTIR spectra were acquired using an Infralum FT-08 from 300 to $4000 \mathrm{~cm}^{-1}$, the samples were prepared by potassium bromide pressed disc technique ( $3 \mathrm{mg}$ of sample with $300 \mathrm{mg}$ of $\mathrm{KBr}$ ). The textural properties were studied by nitrogen adsorption-desorption isotherms at $-196^{\circ} \mathrm{C}$. These measurements were carried out using an Autosorb $1 \mathrm{MP}$ and $\mathrm{iQ}$ (Quantachrome Instruments). All the samples were previously degassed for $12 \mathrm{~h}$ up to a residual pressure lower than $0.5 \mathrm{~Pa}$ at $200{ }^{\circ} \mathrm{C}$. Textural properties were obtained from these isotherms by different methods. The specific surface area $\left(\mathrm{S}_{\mathrm{BET}}\right)$ was assessed by the Brunauer, Emmet, and Teller (BET) method, using the Rouquerol's criteria [27]. The micropore volumes $\left(\mathrm{V}_{\mu \mathrm{p}}\right)$ were calculated with the $\alpha$-plot method using the corresponding sample calcined at $1000{ }^{\circ} \mathrm{C}$ as reference material [28]. 
The total pore volume $\left(\mathrm{V}_{\mathrm{T}}\right)$ was obtained using the Gurvich rule (at 0.97 of relative pressure) [27]. Pore size distributions (PSD) were obtained by the Horvarth-Kawazoe method, considering the adsorption branch and that the PILC have slit shape pores within the interlayer region.

\subsection{Adsorptives: Ciprofloxacin and Tetracycline}

The antibiotics used in this study were ciprofloxacin hydrochloride (CPX, Romikim S.A) and tetracycline hydrochloride (TC, Parafarm). The structures and general characteristics of these two organic compounds are presented in Table 1. Both antibiotics have polifunctional molecules, which implicates that different species are present in the solution depending on the $\mathrm{pH}$ media. The CPX molecule has two pKa values giving three ionic species, the cationic $\left(\mathrm{CPX}^{+}\right)$, the zwiterionic $\left(\mathrm{CPX}^{ \pm}\right)$, and the anionic $\left(\mathrm{CPX}^{-}\right)$. On the other hand, the TC molecule has three protonable-deprotonable groups associated with their pKa values, giving four different ionic species, the cationic $\left(\mathrm{TCH}_{3}{ }^{+}\right)$, the zwiterionic $\left(\mathrm{TCH}_{2}{ }^{ \pm}\right)$, and two anionics $\left(\mathrm{TCH}^{-}\right.$and $\left.\mathrm{TC}^{2-}\right)$. The distribution of antibiotics species at different $\mathrm{pH}$ values were obtained by the method reported by Del Piero et al. [29].

Table 1. General characteristics of the antibiotics used.

\begin{tabular}{|c|c|c|}
\hline & Ciprofloxacin.HCl & Tetracycline.HCl \\
\hline \multicolumn{3}{|l|}{ Structure } \\
\hline Chemical formula & $\mathrm{C}_{17} \mathrm{H}_{18} \mathrm{FN}_{3} \mathrm{O}_{3} \cdot \mathrm{HCl}$ & $\mathrm{C}_{22} \mathrm{H}_{24} \mathrm{~N}_{2} \mathrm{O}_{8} \cdot \mathrm{HCl}$ \\
\hline Molecular weight (g.mol ${ }^{-1}$ ) & 366.80 & 480.90 \\
\hline Molecular dimensions (nm) & $1.2 \times 0.3 \times 0.7[30]$ & $1.2 \times 0.8 \times 1.3[31]$ \\
\hline $\mathrm{pKa}$ & $\mathrm{pKa}_{1}=5.9 ; \mathrm{pKa}_{2}=8.9$ & $\mathrm{pKa}_{1}=3.3 ; \mathrm{pKa}_{2}=7.7 ; \mathrm{pKa}_{3}=9.7$ \\
\hline
\end{tabular}

The protonation-deprotonation reactions that take place at different $\mathrm{pH}$ values of the media also affect the solubility of the antibiotics. In a previous work [16], the solubility of CPX as a function of the complete $\mathrm{pH}$ range was studied. In this work, the solubility curve of TC was obtained from different saturated solutions adjusted at $\mathrm{pH}$ values between 2 and 13 (using $\mathrm{HCl}$ or $\mathrm{NaOH}$, respectively) and kept at $20{ }^{\circ} \mathrm{C}$ for about $12 \mathrm{~h}$ (considering that the equilibrium time was reached). After that, the solutions were filtered and the TC concentration was measured by UV-Vis spectroscopy at the corresponding wavelength.

\subsection{Adsorption Studies}

The adsorption experiments were conducted by mixing $0.02 \mathrm{~g}$ of the adsorbent with $8 \mathrm{~mL}$ of antibiotic solution in tubes of $10 \mathrm{~mL}$ and under stirring at $20^{\circ} \mathrm{C}$ until equilibrium was reached. The values were chosen according to the solubility results. In all the tests, the tubes were wrapped in aluminum foils to prevent light-induced decomposition. After adsorption, the solutions were separated from the adsorbent using a Sorvall RC 5C centrifuge at $8000 \mathrm{rpm}$ for $20 \mathrm{~min}$. The antibiotic equilibrium concentrations in the resultant supernatant were measured with a T60 UV-vis spectrophotometer at $\lambda_{\text {máx }}$ corresponding to the $\mathrm{pH}$ value, from a previously determined calibration curve. All samples were measured in duplicate and the average value was used as isotherm data. The amount of antibiotic adsorbed on the clay mineral $(q)$ was calculated from the initial and equilibrium concentrations, according to Equation (1),

$$
q=\frac{\left(C_{i}-C_{e}\right) * V}{w}
$$


where $V$ is the antibiotic solution volume $(\mathrm{L}), C_{i}$ is the initial antibiotic concentration $\left(\mathrm{mg} . \mathrm{L}^{-1}\right), C_{e}$ is the equilibrium antibiotic concentration $\left(\mathrm{mg} . \mathrm{L}^{-1}\right)$, and $w$ is the mass of clay $(\mathrm{g})$.

\subsection{Modelling Methods}

Adsorption kinetics of antibiotics on NC and Si-PILC were performed using an initial fixed antibiotic concentration (110 mg. $\mathrm{L}^{-1}$ for CPX and $480 \mathrm{mg} . \mathrm{L}^{-1} \mathrm{TC}$, respectively) with contact times varying between 0.5 and $24 \mathrm{~h}$. The kinetics studies were useful to assess the contact time required to reach equilibrium. In order to acquire additional information about adsorption mechanisms, experimental data were fitted to the pseudo-first-order, pseudo-second-order, and intraparticle diffusion models [16,18,32,33].

The Lagergren pseudo-first order equation can be expressed as (Equation (2)):

$$
q_{t}=q_{e}\left(1-e^{\left(-k_{1} t\right)}\right)
$$

where $q_{t}$ is the amount of antibiotic adsorbed at time $t$ (mg.g $\left.{ }^{-1}\right), q_{e}$ is the equilibrium adsorption capacity of the adsorbent $\left(\mathrm{mg} \cdot \mathrm{g}^{-1}\right)$, and $k_{1}$ is the rate constant of pseudo first-order kinetics $\left(\mathrm{min}^{-1}\right)$.

Similarly, if the mechanism is thought to be pseudo-second order kinetic, the equation can be expressed as (Equation (3)):

$$
q_{t}=\frac{k_{2} q_{e}^{2} t}{1+k_{2} q_{e} t}
$$

where $q_{t}$ is the amount of antibiotic adsorbed at time $t$ (mg. $\left.\mathrm{g}^{-1}\right), q_{e}$ is the equilibrium adsorption capacity of the adsorbent (mg. $\left.\mathrm{g}^{-1}\right)$, and $k_{2}$ is the rate constant of pseudo second-order kinetics (g.mg. $\mathrm{min}^{-1}$ ).

The intraparticle diffusion model was derived from Fick's second law of diffusion and assumes that intraparticle diffusion is the rate limiting step, the film diffusion can be negligible at the beginning of diffusion and the intraparticle diffusivity is constant. The equation of the intraparticle diffusion model can be expressed as it is shown in Equation (4). Thus, the plot of $q_{t}$ versus $t^{0.5}$ can give one straight line or shows multilinearity which can be related to different diffusion mechanisms [18,33].

$$
q_{t}=k_{d} t^{0.5}
$$

where $q_{t}$ is the amount adsorbed (mg.g $\left.{ }^{-1}\right)$ at time $t$ and $k_{d}$ is the intraparticle-diffusion parameter (mg.g ${ }^{-1} \min ^{-0.5}$ ).

The adsorption equilibrium data were fitted to Langmuir, Freundlich, and Sips isotherm models [34]. The Langmuir model assumes one adsorption energetically equivalent without interactions among the adsorbed neighbor molecules on a homogeneous surface. The mathematical expression of the Langmuir model is shown in Equation (5):

$$
q=\frac{q_{m} k C_{e q}}{1+k C_{e q}}
$$

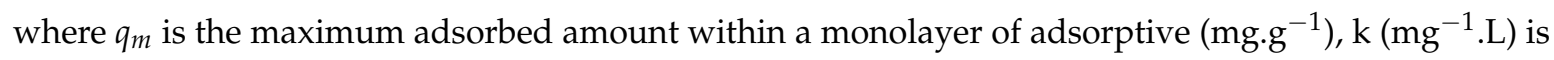
the Langmuir dissociation constant, which is related to the adsorption energy, and $C_{e q}$ has the same meaning as above.

The Freundlich equation is commonly used for multisite adsorption isotherms, it is an empirical method related to adsorption on heterogeneous surfaces and its mathematical expression is (Equation (6)):

$$
q=k_{f} C_{e}^{1 / n}
$$

where $k_{f}\left(\mathrm{~L} . \mathrm{g}^{-1}\right)$ and $n$ (dimensionless) are the Freundlich characteristic constants, indicating the adsorption capacity and adsorption intensity, respectively. 
The third isotherm model is considered as a combination of the Langmuir and Freundlich equations and is called the Sips model. It is also an empirical equation, related to more heterogeneous adsorption systems without adsorbate-adsorbate interactions; its mathematical expression is shown in Equation (7).

$$
q=q_{m} \frac{\left(b C_{e}\right)^{1 / n}}{1+\left(b C_{e}\right)^{1 / n}}
$$

where $q_{m}$ and $C_{e}$ have the same meanings as above, $b$ is a parameter related to the affinity of the adsorbate towards the surface, and $n$ is a parameter that represents the heterogeneity of the system.

The Scatchard plots were built by transformation of the isotherm data to obtain a plot of $q / C_{e}$ versus $q$ (where $q$ and $C_{e}$ have the same meanings indicated above). The shape of the Scatchard plot can be useful to acquire complementary information about the adsorption phenomena $[25,35,36]$.

\section{Results and Discussion}

\subsection{Adsorbents Characterization}

XRD patterns obtained for the natural and Si-PILC clays and their main fractions are shown in Figure 1A. The obtained XRD pattern for the NC exhibits a basal distance $\left(\mathrm{d}_{001}\right)$ of $1.26 \mathrm{~nm}$, which is typical of natural sodic montmorillonite. The Si-PILC diffractograms did not show any defined peaks in the range in which the basal distance should be present. Furthermore, there are no other structural changes in the PILC in reference to the raw material $[37,38]$. In order to evaluate the existence of an increase in the basal distance $\left(\mathrm{d}_{001}\right), \mathrm{XRD}$ at low angle was obtained for the Si-PILC 75 and is shown in Figure 1B. A basal distance of $4.32 \mathrm{~nm}$ was found for this material, which evidences the presence of silica oxide species within the interlayer clay suggesting an effective pillarization process. This result agrees with the values reported by other authors [26]. Si-PILC 25 and 50 were not analyzed at low angle but a similar behavior could expect for them.
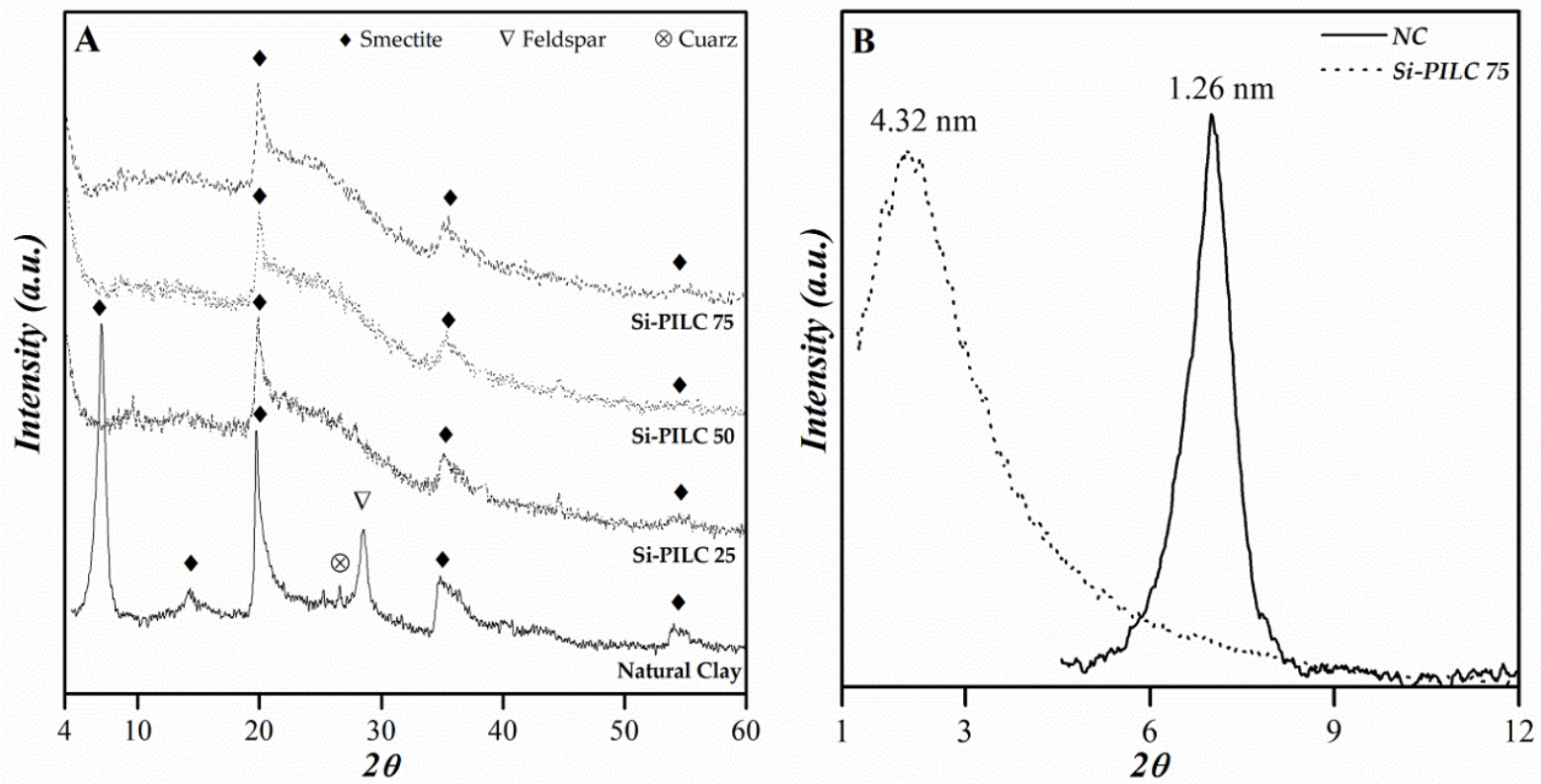

Figure 1. XRD patterns of NC and Si-PILC. (XRD: X-Ray Diffraction.)

The FTIR spectra obtained for the four materials and their main bands are shown in Figure 2. The natural clay spectrum is in accordance with previous reports, where the absorption bands at 3630,3454 , and $1640 \mathrm{~cm}^{-1}$ are typical for smectites and associated to tension vibrations of the $\mathrm{O}-\mathrm{H}$ bond in hydroxyl groups of dioctahedral structures and $\mathrm{H}-\mathrm{O}-\mathrm{H}$ vibrations of water molecules weakly 
hydrogen bonded to the $\mathrm{Si}-\mathrm{O}$ surface, respectively [26,39]. In addition, the bands found at 1040, 800, 524 , and $470 \mathrm{~cm}^{-1}$ are attributed to $\mathrm{Si}-\mathrm{O}$ stretching vibrations, $\mathrm{Si}-\mathrm{O}-\mathrm{Al}$ (octahedral $\mathrm{Al}$ ) and $\mathrm{Si}-\mathrm{O}-\mathrm{Si}$ bending vibrations, respectively. The spectra obtained for the Si-PILC show a considerable reduction of the bands related to water presence and $\mathrm{O}-\mathrm{H}$ vibrations, which could be due to the acid treatment used during the synthesis of these materials $[26,39]$. Additionally, the spectra of the Si-PILC show increments in the bands of 1200 and $800 \mathrm{~cm}^{-1}$ which evidences the increase of Si-O-Si bonds in their structures as a consequence of the pillaring process.

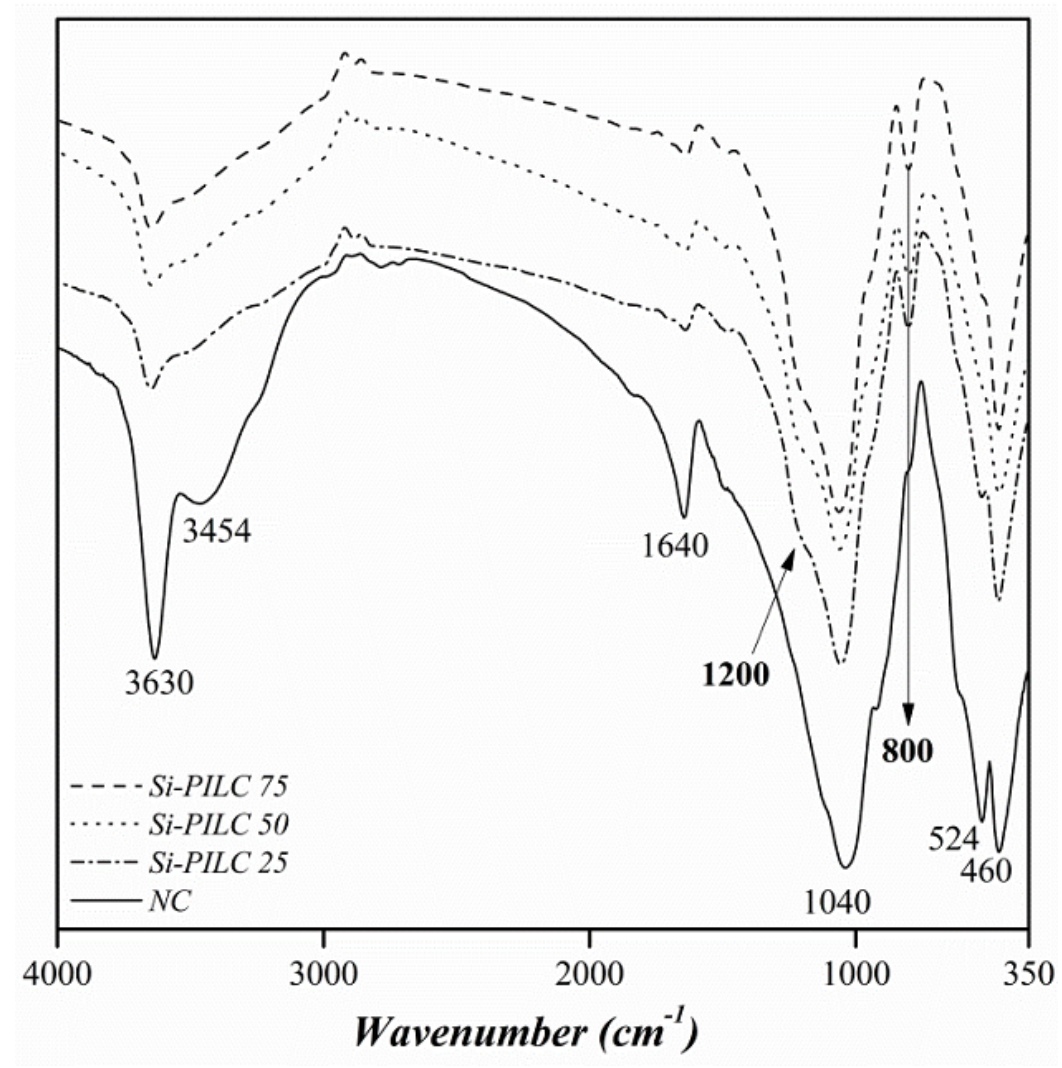

Figure 2. FTIR spectra for the natural and Si-pillared clays.

Nitrogen adsorption-desorption isotherms at $-196{ }^{\circ} \mathrm{C}$ obtained from the materials are shown in Figure 3. The natural clay isotherm is classified as type $\mathrm{Ilb}$ with an $\mathrm{H} 3$ hysteresis loop according to the International Pure and Applied Chemistry (IUPAC) classification which is associated with mesoporous materials with aggregates of plate-like like the montmorillonites $[27,40]$. The isotherms obtained for Si-PILC can be classified as a combination between type I and IIb. The first one is due to the high amount adsorbed at low relative pressures related to the presence of microporosity in the PILC structures generated after the pillaring process. The second one is associated with the growth of the adsorption in the mono-multilayer region.

Hysteresis loops were observed for the three Si-PILC demonstrating the presence of mesoporosity in their structures. The type of hysteresis loop is classified as type H4 according to the IUPAC and it is associated with slit-like pores as well as the pores generated within the interlayer of the clay minerals $[27,40]$. As can be seen, all the pillared clays present higher adsorption at low relative pressures than the natural clay, which is associated with their microporosity and evidences a successful pillaring process. However, among the pillared clays Si-PILC 50 showed the highest adsorption at low relative pressure suggesting there is not a correlation between the adsorption increase observed and the $\mathrm{Si}$ /clay ratio used during the synthesis process. This could be due to the amount of siliceous 
present in the interlayer for the Si-PILC 75 which could generate higher pillars density than the Si-PILC 50 implicating a lower microporosity.

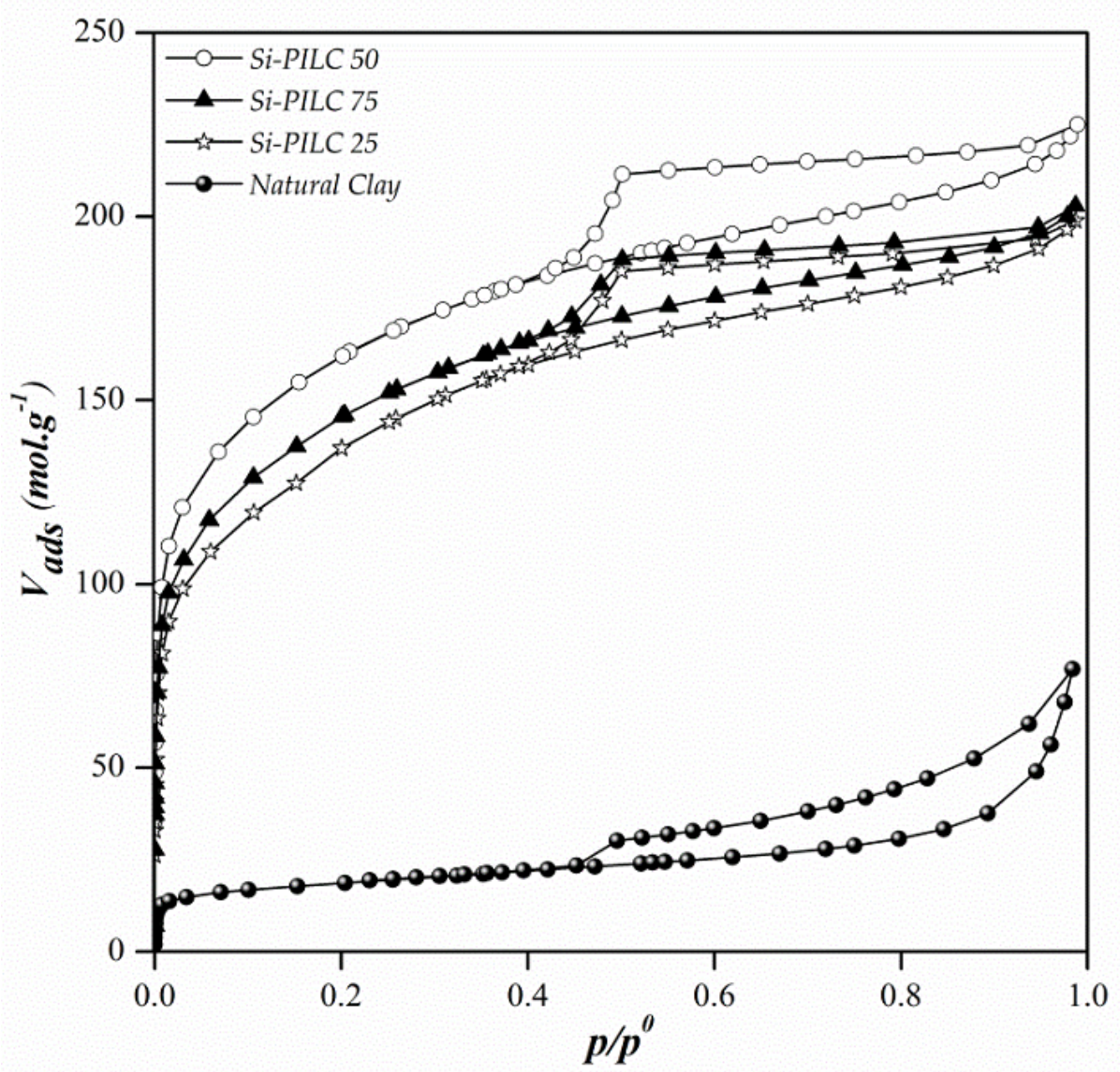

Figure 3. $\mathrm{N}_{2}$ adsorption-desorption isotherms for the four materials.

Textural properties for all materials were obtained from the $\mathrm{N}_{2}$ adsorption-desorption isotherms and are summarized in Table 2. Significant increases in the specific surface areas ( $\mathrm{S}_{\mathrm{BET}}$ ) for the Si-PILC with regard to the natural clay are observed, reaching nine times the NC value for the Si-PILC 50. This last is related to the increase in the microporosity of these materials resulting in 57,65, and $61 \%$ for the Si-PILC 25, 50, and 75, respectively. The $S_{\text {BET }}$ and micropores volume $\left(V_{\mu p}\right)$ values increased from Si-PILC 25 to Si-PILC 75 and Si-PILC 50, respectively, and it is associated with the amount of micropores present in their structures. The fact that Si-PILC 75 showed lower values than Si-PILC 50 could be due to the amount of pillaring agent added. The results suggest that $\mathrm{Si}$ /clay ratio higher than $50 \mathrm{~mol} \mathrm{Si.g^{-1 }}$ could generate more pillars density within the clay interlayer which during the heating treatment could collapse, decreasing the microporosity. The $\mathrm{V}_{\mathrm{T}}$ values supported the behavior of the isotherms at high relative pressures obtaining the highest value for the Si-PILC 50.

Table 2. Textural properties for the materials. (PILC: pillared clays.)

\begin{tabular}{cccc}
\hline & $\mathbf{S}_{\mathbf{B E T}}\left(\mathbf{m}^{\mathbf{2}} \cdot \mathbf{g}^{-\mathbf{1}}\right)$ & $\mathbf{V}_{\mathbf{T}}\left(\mathbf{c m}^{\mathbf{3}} \cdot \mathbf{g}^{-\mathbf{1}}\right)$ & $\mathbf{V}_{\boldsymbol{\mu p}}\left(\mathbf{c m}^{\mathbf{3}} \cdot \mathbf{g}^{-\mathbf{1}}\right)$ \\
\hline Natural Clay & 67 & 0.10 & 0.01 \\
Si-PILC 25 & 485 & 0.30 & 0.17 \\
Si-PILC 50 & 585 & 0.34 & 0.22 \\
Si-PILC 75 & 519 & 0.31 & 0.19 \\
\hline
\end{tabular}


The PSD for the PILC and NC were studied in the micropores region (pores size below $2 \mathrm{~nm}$ ) and are shown in Figure 4. As can be observed, the microporosity in the natural clay is considerably lower than that obtained for the pillared clay, which is in accordance with the textural results. All pillared clays have micropore sizes between 0.5 and $2 \mathrm{~nm}$, whereas Si-PILC 25 and 50 showed similar distributions with micropore sizes approximately $0.75 \mathrm{~nm}$. Si-PILC 75 shows contribution of smaller pore sizes (near to $0.7 \mathrm{~nm}$ ) than the other PILC, suggesting the greater pillar density within the interlayer due to the high $\mathrm{Si} /$ clay ratio.

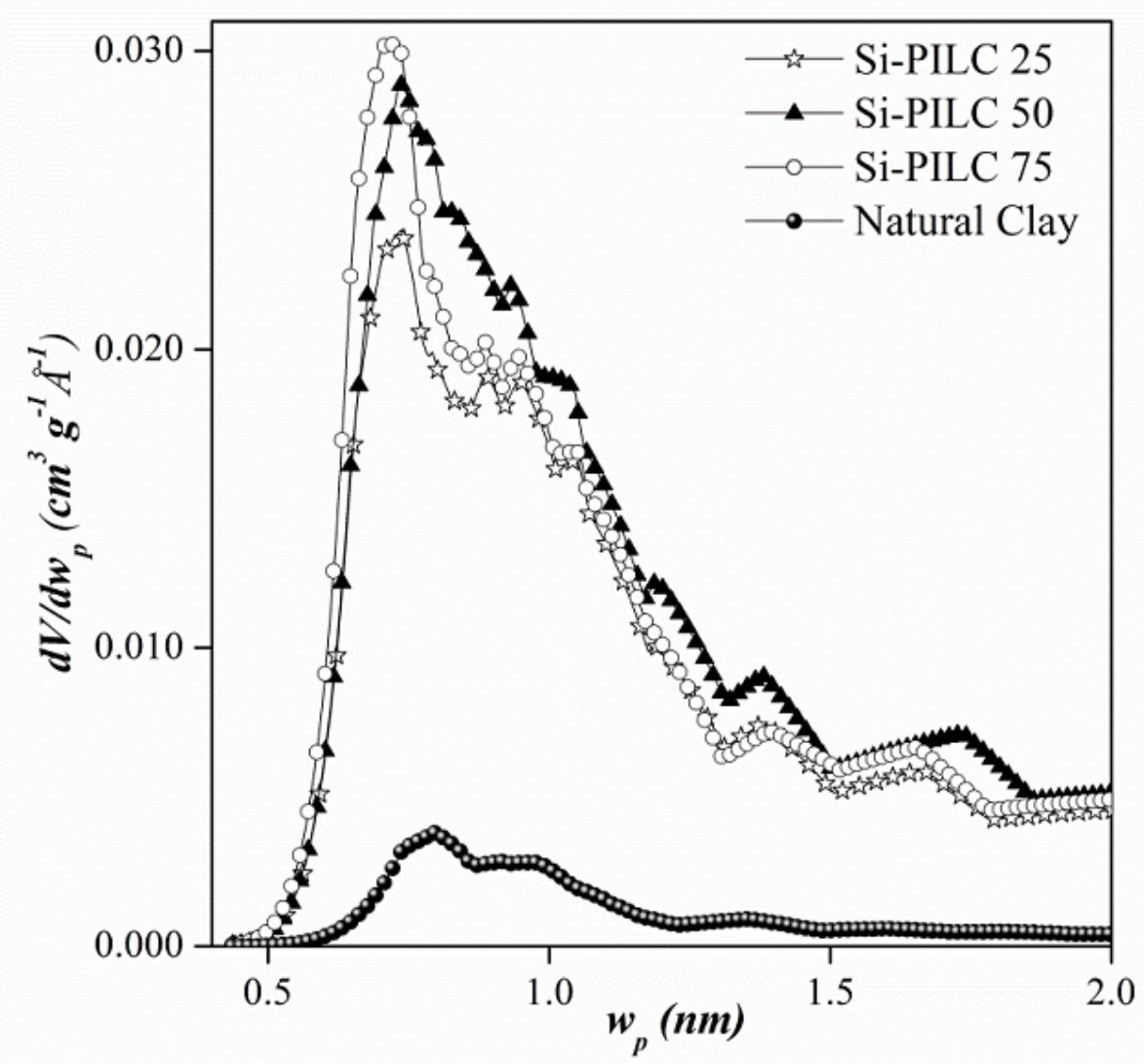

Figure 4. Pore size distribution (PSD) of natural and pillared clay minerals.

\subsection{Effect of the $p H$ Media on the Adsorption}

The presence of protonable groups in the antibiotics molecules generates different species according to the media $\mathrm{pH}$. Thus, the species present in the aqueous solution and their solubility depend on the $\mathrm{pH}$; this also influences their interaction with the adsorbent surfaces. In a previous work, the strong correlation between the solubility in water and the adsorption on clay of CPX with the $\mathrm{pH}$ of the media was shown [16]. The tetracycline solubility curves in water with its distribution of species as a function of the media $\mathrm{pH}$ are shown in Figure 5. The solubility behavior can be explained considering the species present within each $\mathrm{pH}$ range. As was mentioned above, the TC molecule has three $\mathrm{pK}_{\mathrm{a}}$ values which implicate the existence of four possible species in solution. At the lowest $\mathrm{pH}$ values the soluble cationic TC species $\left(\mathrm{TCH}_{3}^{+}\right)$is present and its percentage decreases from $\mathrm{pH}$ 2 to $3.3\left(\mathrm{pK}_{\mathrm{a} 1}\right)$ as well as its solubility. In the $\mathrm{pH}$ range from 3.3 to $7.7\left(\mathrm{pK}_{\mathrm{a} 2}\right)$ three TC species exist, where the zwitterion form $\left(\mathrm{TCH}_{2}^{ \pm}\right)$is the predominant one, reaching the lowest solubility due to its neutral charge. Later increases in the media $\mathrm{pH}$ generate the increase in solubility because TC turns into its anionic forms, $\mathrm{TCH}^{-}$(between $\mathrm{pH}$ values of 7.7 and 9.7) and $\mathrm{TC}^{2-}$ ( $\mathrm{pH}$ values higher than 9.7). Thus, analogously to the results for CPX, TC is more soluble when the ionic forms are present in the media and shows the lowest solubility around a $\mathrm{pH}$ value of 4.8 because at this $\mathrm{pH}$ it has the highest 
zwitterion percentage. Additionally, it is known that due to the existence of asymmetric carbon atoms in the TC molecule, its species in solution can adopt two possible conformations called the extended and twisted conformation [41]. The first one is predominant in basic media, whereas the second one in neutral or acid media. This must be taken into consideration because according to the conformation the molecular size can suffer changes.

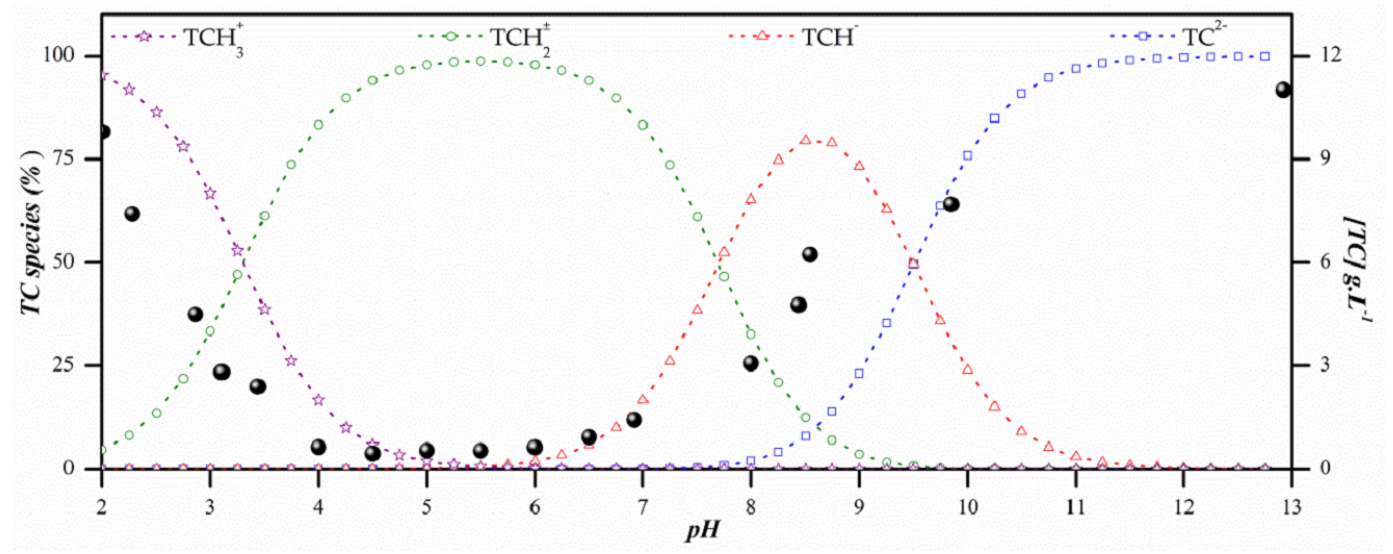

Figure 5. TC solubility curve and distribution of species as function of $\mathrm{pH}$ media.

The studies of antibiotic adsorption on NC and Si-PILC 75 at different $\mathrm{pH}$ values were assessed under the above mentioned conditions with an initial fixed concentration of 110 and $480 \mathrm{mg} . \mathrm{L}^{-1}$ for CPX and TC, respectively. The $\mathrm{pH}$ of the initial solution was adjusted to values between 3 and 10 using $\mathrm{HCl}$ or $\mathrm{NaOH}$ solutions. These values were chosen based on the antibiotics solubility curves and considering the species present in each $\mathrm{pH}$ range [16]. The adsorption capacity of CPX and TC on NC and Si-PILC 75 at different $\mathrm{pH}$ values are shown in Figure 6. In the case of TC, its adsorption on NC showed a behavior similar to the reported by other authors, where the highest adsorption occurs at low $\mathrm{pH}$ values, when the $\mathrm{TCH}_{3}^{+}$species is present and the adsorption is governed mainly by electrostatic interactions [42]. The cationic form of TC is adsorbed on the negative charge surface of the NC mainly by cation exchange for the natural cation within the montmorillonite interlayer [42,43]. After that, at $\mathrm{pH}$ values greater than 4 the adsorption decreases with increases in $\mathrm{pH}$ because the TC transitions into zwitterionic and anionic forms. At these $\mathrm{pH}$ values, the species could be adsorbed on the mineral negative surface by other adsorption mechanisms like hydrophobic interactions, hydrogen bonding, or inner sphere complexes. However, it is important to consider that at $\mathrm{pH}$ values lower than $10, \mathrm{TCH}_{2}^{ \pm}$and $\mathrm{TCH}^{-}$species have net charges of zero and one, respectively, but the amine group is protonated in their structures. This could favor the adsorption of these species on the negatively charged surface of the natural clay. Other authors proposed that when these species are adsorbed within the interlayer clay, they arrange at the surface so that the positively charged group is located close to the surface sites and their negatively charged part is driven as far away as possible from the surface [42,43]. The lowest TC adsorption was obtained at $\mathrm{pH}$ values higher than 9.7, where the main species was the $\mathrm{TC}^{2-}$ and it was probably because of the repulsion with the negatively charged surface of the NC. The TC adsorption on Si-PILC 75 was considerably lower than that obtained for the NC in all the $\mathrm{pH}$ range except to values up to 8.5. No greater differences in the amount of TC adsorbed on pillared clay were observed in the whole $\mathrm{pH}$ range. This could suggest that the interactions between the TC species and the pillared clay surface are low, or that the porous structure of this material could be avoiding the molecule access to the adsorption sites. The adsorption of CPX on natural clay showed a similar behavior to the TC adsorption, were the highest adsorptions were obtained at low $\mathrm{pH}$ values with a maximum at $\mathrm{pH}$ 6; decreasing when the $\mathrm{pH}$ increases. These results can be explained similarly to those above; at low $\mathrm{pH}$ values the $\mathrm{CPX}^{+}$is present and is adsorbed on the negative surface of the natural clay by cation exchange. After that, at $\mathrm{pH}$ values of $7.5, \mathrm{CPX}^{ \pm}$and $\mathrm{CPX}^{-}$are present in 
the solution, decreasing the adsorption and resulting in other adsorption mechanisms [16]. Results shown for the adsorption of CPX on Si-PILC 75 evidenced that there are no variations in the amount adsorbed at different $\mathrm{pH}$ values, decreasing with an increase in the $\mathrm{pH}$. However, the adsorption for this material under basic conditions (up to $7.5 \mathrm{pH}$ ) was higher than for the natural clay, suggesting that Si-PILC interacts with the CPX species by another mechanism, like the formation of an inner sphere complex $[25,44]$.
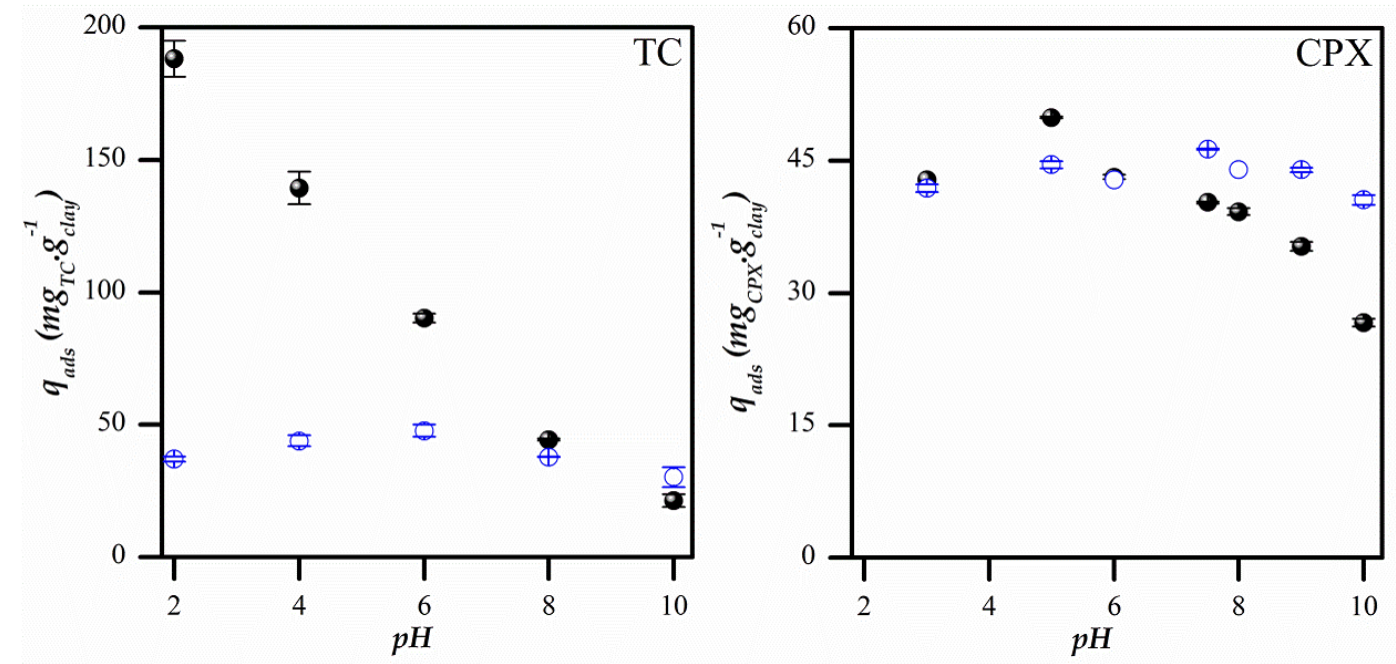

Figure 6. Effect of media $\mathrm{pH}$ on CPX and TC adsorption where the full and empty symbols are NC ( and Si-PILC $75(\bigcirc)$, respectively.

\subsection{Adsorption Kinetics}

Adsorption kinetics of both antibiotics on NC and Si-PILC 75 were evaluated at $\mathrm{pH}$ values of 8.5 and 10 for TC and CPX, respectively, so that the species in solution were anionic in order to evaluate their interactions with the surfaces materials. The experiments were performed using the same initial and fixed concentrations than above, 110 and $480 \mathrm{mg} \cdot \mathrm{L}^{-1}$ for CPX and TC with contact times varying between 0.5 and $24 \mathrm{~h}$. Adsorption kinetic curves obtained for the Si-PILC 75 and their fitting to the pseudo-first and pseudo-second order are shown in Figure 7. For the adsorption on $\mathrm{NC}$, the results showed that the adsorption equilibrium is rapidly reached for TC and is lower for CPX (around $4 \mathrm{~h}$ ). These results could be due to the species present in each case. For the TC at a pH value of 8.5 , the species present is $\mathrm{TCH}^{-}$and its structure still has a positively charged group. This last favors the adsorption on the negative surface of the $\mathrm{NC}$ by cation exchange, implicating a fast adsorption. In the case of $\mathrm{CPX}$ at a $\mathrm{pH}$ value of 10 , the species present is anionic and the higher time to reach the equilibrium could be due to the fact that the adsorption mechanism is not cation exchange. No significant differences were obtained among the data, indicating that the equilibrium of the systems was reached, and therefore the kinetic studies on NC were not fitted to the models. The TC adsorption on Si-PILC 75 reached equilibrium at around $7 \mathrm{~h}$, what could be due to the fact that the pillared clay porous structure is limiting the access of the TC molecule to the interlayer region and delaying the adsorption. This implicates that the adsorption mechanism in the Si-PILC is different from the one proposed for the NC. The results obtained for CPX on Si-PILC 75 are similar to those obtained for TC, the system reaches the equilibrium at a contact time of $8 \mathrm{~h}$. This supports the fact that in the pillared clay its microporous structure could be avoiding the access of the molecules to the interlayer region generating a slower adsorption process. 


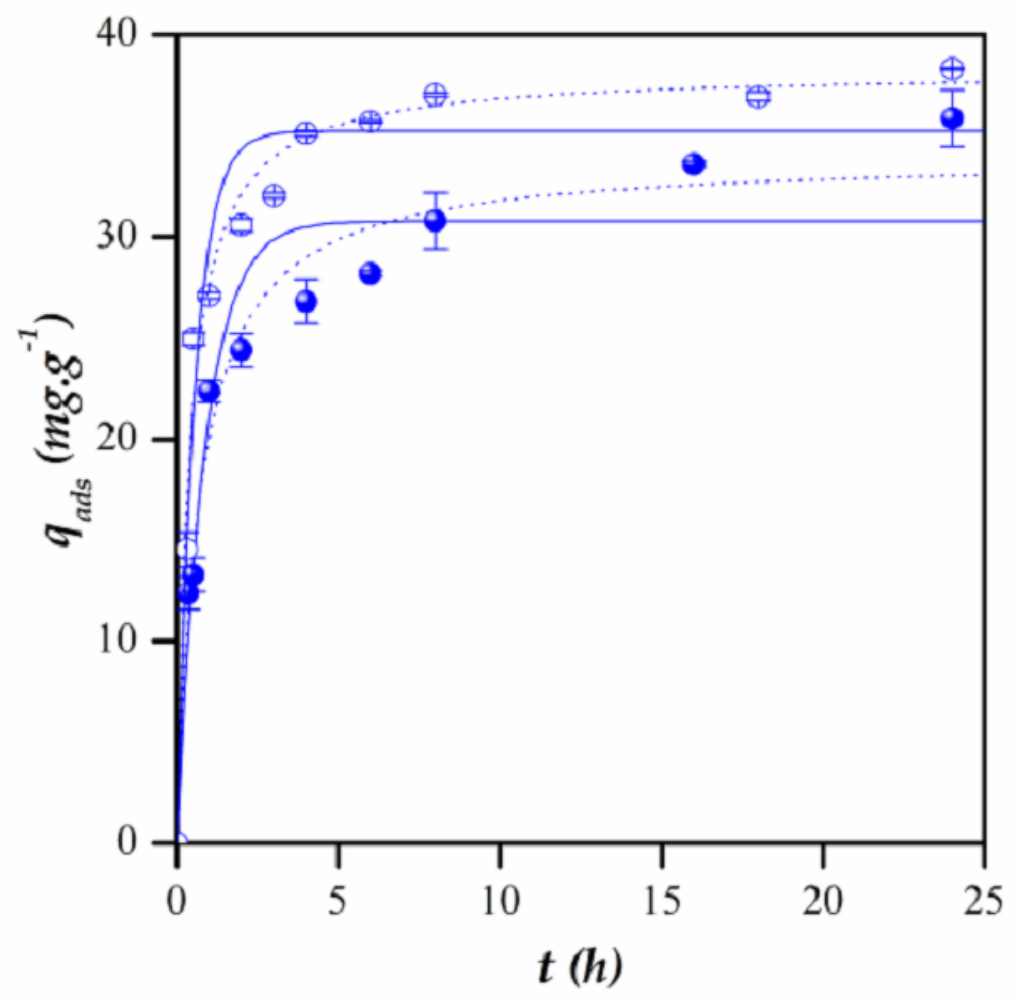

Figure 7. Kinetic adsorption data for TC $(\bullet)$ and CPX $(\mathrm{O})$ on Si-PILC 75. Solid lines represent a pseudo-first-order model and dot lines represent pseudo-second order model.

The adsorption kinetic parameters were estimated by nonlinear regression of pseudo-first and pseudo-second order equations and for two materials [32,45]. The obtained values are in good agreement with the previously shown results obtained for the adsorption vs. $\mathrm{pH}$ curves and are summarized in Table 3. As can be seen from the table, all the regression coefficients are higher than 0.90. However, if the studied systems are considered, the second-order model is more appropriate due to the fact that it is based on the sorption capacity of the solid and it considers that the rate controlling step is the chemical or electrostatic change generated in the system [32,44,45]. In addition, the $k_{2}$ values agree with the fact that natural clay requires lower time than the pillared clay to reach equilibrium in both systems. For the kinetics adsorption results shown, an equilibrium time of $24 \mathrm{~h}$ was chosen to perform the adsorption isotherms.

In order to acquire more information regarding the adsorption process on the pillared clay, the intraparticle model was used and the results obtained are shown in Figure 8. As can be seen from this figure, the plots resulted in two different straight lines with regressions that do not pass through the origin, indicating that intraparticle diffusion was not the only rate controlling step. This could be related to the existence of an initial external mass transfer or a chemical reaction between the antibiotic molecule and the adsorbent surface [33]. The slopes of the linear regressions $\left(\mathrm{k}_{3}{ }_{3}\right.$ and $\mathrm{k}_{3}{ }_{3}$ in Table 3) indicate the rate of the adsorption process. The values obtained for the intraparticle diffusion parameters indicate the decrease of the diffusion rates with the increase of the contact time for both antibiotics. These results evidenced that as the antibiotic molecules diffused into the pillared clay structure, the pores aviable for diffusion decreased, limiting the adsorption. Thus, the first section is related to the stage in which the antibiotics are rapidly adsorbed on the PILC surface, which could be related to the microporous structure. The second section is related to the adsorption on the external surface, which contains the mesoporous structure. Similar results were reported for the adsorption of dyes on pillared clays [18]. 
Table 3. Pseudo-first-, -second-order, and intraparticle rate parameters for TC and CPX on Si-PILC 75.

\begin{tabular}{|c|c|c|c|}
\hline & & TC & CPX \\
\hline & & pH 8.5 & pH 10 \\
\hline \multirow{3}{*}{ Pseudo first order } & $q_{e}\left(\mathrm{mg} \cdot \mathrm{g}^{-1}\right)$ & 30.8 & 35.2 \\
\hline & $k_{1}\left(1 \min ^{-1}\right)$ & 1.10 & 1.86 \\
\hline & $R^{2}$ & 0.93 & 0.93 \\
\hline \multirow{3}{*}{ Pseudo second order } & $q_{e}\left(\mathrm{mg} \cdot \mathrm{g}^{-1}\right)$ & 33.9 & 3.21 \\
\hline & $k_{2}\left(\mathrm{~g}(\mathrm{mg} \cdot \min )^{-1}\right)$ & 0.04 & 0.07 \\
\hline & $R^{2}$ & 0.98 & 0.98 \\
\hline \multirow{4}{*}{ Intraparticle } & $k_{3}^{\prime}\left(\mathrm{mg} \cdot\left(\mathrm{g} \cdot \min ^{0.5}\right)^{-1}\right)$ & 1.91 & 0.92 \\
\hline & $R^{2}$ & 0.99 & 0.99 \\
\hline & $k_{3}{ }_{3}\left(\mathrm{mg} \cdot\left(\mathrm{g} \cdot \mathrm{min}^{0.5}\right)^{-1}\right)$ & 0.40 & 0.13 \\
\hline & $R^{2}$ & 0.97 & 0.95 \\
\hline
\end{tabular}

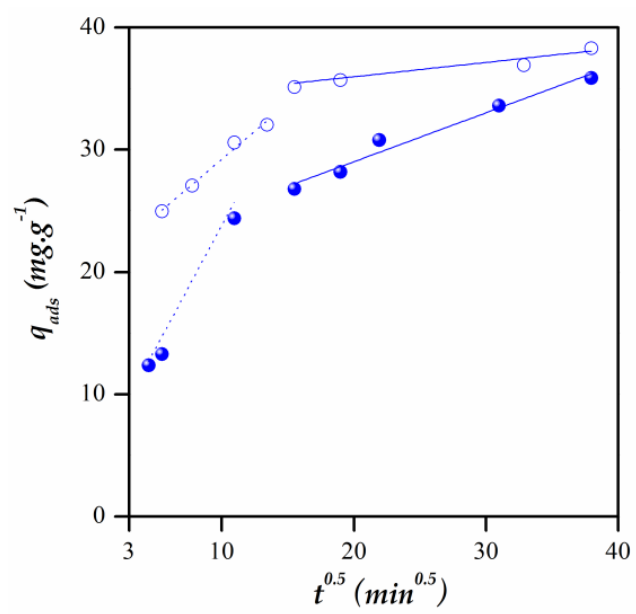

Figure 8. Intraparticle diffusion model for the adsorption of TC $(\bullet)$ and CPX $(\mathrm{O})$ on Si-PILC 75.

\subsection{Adsorption Isotherms}

The batch adsorption experiments were performed in the conditions mentioned above varying the initial concentrations between $40-610 \mathrm{mg} . \mathrm{L}^{-1}$ for the TC and 18-500 mg. $\mathrm{L}^{-1}$ for the CPX. The contact time was set to a period of $24 \mathrm{~h}$ and the contact solutions were set at $\mathrm{pH} 8.5$ and 10 for TC and CPX, respectively. These values were chosen based on the results previously shown and in order to evaluate the behavior of the clays adsorption when the species with a net charge of -1 are present $\left(\mathrm{CPX}^{-}\right.$ and $\mathrm{TCH}^{-}$). The adsorption isotherms obtained for the antibiotics on four materials and their best adjustments are shown in Figure 9. Taking into account the Giles et al. classification [46], different behaviors can be associated with the isotherm shapes obtained. For the adsorption of TC on the natural clay, the isotherm can be classified as sigmoidal type ( $\mathrm{S}$ type) which is considered to be a result of two opposite mechanism. In first place the $\mathrm{TCH}^{-}$species has a low affinity towards the negative surface of the clay but once some molecules are adsorbed, they can become new adsorption sites favoring subsequent adsorptions. This phenomenon is called cooperative adsorption and the isotherm saturation point occurs when no vacant sites remain [46,47]. The isotherms obtained for the adsorption of TC on pillared clays showed some differences among them. The Si-PILC 50 and 75 isotherms can be classified as high affinity type (H-type) and the one obtained for the Si-PILC 25 was a Langmuir type (L-type). Both types of isotherms are obtained when the saturation of solid sites is progressive until reaching its limited adsorption capacity [46,47]. The H-type isotherm is usually associated with the adsorption of ionic solutes, where the competition between adsorptive and solvent 
molecules is low. This could be the result of the higher hydrophobicity exhibited by the pillared clays in contrast with the natural clay. Also, these results evidenced that pillared clays have more affinity for the $\mathrm{TCH}^{-}$species present in solution than natural clay. The high affinity shown suggests that the adsorption occurs by a different mechanism and it could be due to the presence of new adsorption sites on the surface of the pillared clays associated with the pillars. Additionally, Si-PILC 25 was the pillared clay with the lowest affinity but the highest adsorption capacity and this could be explained considering that it was the material with the lowest ratio Si/clay. This could implicate that the Si-PILC 25 interlayer region has probably lower pillars density resulting in a porous structure that favors the interaction between the TC species and the pillars. The adsorption isotherms obtained for CPX can be classified as H-type for Si-PILC 50 and 25 and L-type for Si-PILC 75 and NC. Their analysis is similar to the one done for TC adsorption, all the pillared clays showed a higher affinity towards the $\mathrm{CPX}^{-}$ than the natural clay. The natural clay isotherm suggests a lower affinity of the anionic CPX species present towards the more negatively charged clay than the one observed for the PILC. As in the case of the TC adsorption, this last could be due to a combination of the adsorption mechanism and the hydrophobicity of these materials.

As can be seen in Figure 9, all the materials showed higher CPX adsorption capacities than those obtained for TC adsorption. The adsorption results obtained for the NC evidences that it has higher affinity and adsorption capacity for the $\mathrm{CPX}^{-}$than for the $\mathrm{TCH}^{-}$, even when these species still have a protonated group in their structure. These results may suggest that these two species are adsorbed in different ways on the natural clay, where $\mathrm{TCH}^{-}$is probably adsorbed within the interlayer region, whereas the $\mathrm{CPX}^{-}$interacts with adsorption sites on the clay surface. Further work is required to stablish this idea.

In the case of the Si-PILC, the results evidenced that these materials have a considerably higher affinity and adsorption capacities for the CPX species than for the TC which could be related to the access that the molecules have to the porous structures. In a previous work, the adsorption of CPX on different pillared clays in alkaline media was proposed as result of a combination of two effects. The first one was the porous structure of the PILC limiting the molecule access to the pillared structure, and the other one was the adsorption of the anionic species by inner sphere complex formation with the pillars' adsorption sites [25]. Taking into account the criteria proposed in that work about the porous size needed for the molecules to access to the pillared structure, and considering that the molecules diffuse into the porous structure of the adsorbents lengthwise, the adsorption results could be explained. At alkaline $\mathrm{pH}$, TC shows its extended conformation with dimensions of $1.2 \times 0.8 \times 1.3 \mathrm{~nm}$ which implicates that the size needed to be adsorbed is $1.4 \mathrm{~nm}$, whereas for the $\mathrm{CPX}$, the size is $1.3 \mathrm{~nm}$. There are no significant differences between these two values but considering the dimensions of CPX $(1.2 \times 0.3 \times 0.7 \mathrm{~nm})$, its highest adsorption could be explained. Also, this may indicate that the $\mathrm{CPX}$ molecule has more access to the pillar structure that favors its interaction with the pillars.

All the adsorption data obtained were fitted to Freundlich, Langmuir, and Sips models and their fitting parameters are summarized in Table 4. Considering the results obtained for TC adsorption on NC and Si-PILC 25, Langmuir and Sips models, respectively, are not shown because they have a higher percentage error associated, suggesting that the adsorption does not agree with the assumptions proposed in those models. As can be seen from the Table 4, the best fittings were obtained for the Sips model in all the systems under study. These results are likely related to the fact that there are more heterogeneous adsorption systems which could be generated for the different adsorption sites on the solid surfaces, the adsorptive species or, a combination of them. Regarding the adsorption on the NC, the heterogeneity could be associated to the hydrophobic effect of the solvent towards the antibiotics molecules generating the adsorption as result of its repulsion against the solvent from the solution [25]. This is in accordance with the obtained values for the $b$ parameter for NC systems which suggest that these systems have the lowest affinity of the adsorbates towards the surface. It could be explained for the species present for each antibiotic which are negatively charged, and its adsorption probably 
occurs by different adsorption short-range forces such as hydrophobic bonding, hydrogen bridges, steric, or orientation effects. These results are according to those mentioned above. In the case of the antibiotics adsorption on Si-PILC, the hydrophobic effect possibly influences in the same way of the $\mathrm{NC}$, but with the highest $n$ values, suggesting more heterogeneous systems. This higher heterogeneity for the PILC compared to the NC could be related to the new adsorption sites generated by the pillars presence and their porous structures. The results showed that for all the PILC materials, the systems for CPX have higher adsorption capacities than for TC and are also more heterogeneous. This can be related to the molecule size, due to the fact that the CPX size is lower than the TC size, allowing more access for $\mathrm{CPX}$ to the porous structure and resulting in higher adsorptions and affinities than the TC species. Finally, regarding the adsorption of TC on Si-PILC, the highest adsorption capacity was obtained for Si-PILC 25, and the best fit was obtained with the Freundlich model, suggesting that for this material the adsorption occurs on heterogeneous sites. This last result could be related to the lower amount of micropores in the Si-PILC 25 structure which could allow more access of the $\mathrm{TCH}^{-}$ species to the adsorption sites.

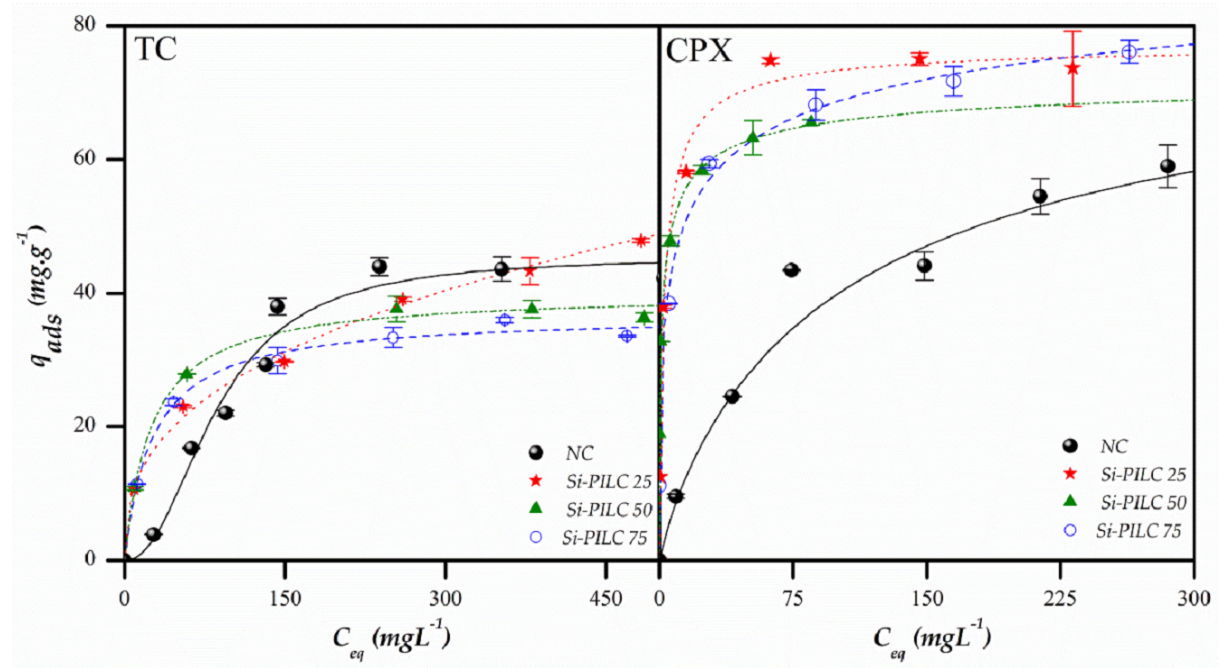

Figure 9. Experimental isotherms (symbols) and their best equations adjustments for the equilibrium adsorption data of TC and CPX on natural and pillared clays.

Table 4. Freundlich and Langmuir parameters for CPX and TC adsorption on natural and pillared clay minerals.

\begin{tabular}{|c|c|c|c|c|c|c|c|c|c|}
\hline & & \multicolumn{4}{|c|}{ TC } & \multicolumn{4}{|c|}{ CPX } \\
\hline & & NC & $\begin{array}{l}\text { Si-PILC } \\
25\end{array}$ & $\begin{array}{c}\text { Si-PILC } \\
50\end{array}$ & $\begin{array}{c}\text { Si-PILC } \\
75\end{array}$ & NC & $\begin{array}{c}\text { Si-PILC } \\
25\end{array}$ & $\begin{array}{c}\text { Si-PILC } \\
50\end{array}$ & $\begin{array}{l}\text { Si-PILC } \\
\quad 75\end{array}$ \\
\hline \multirow{3}{*}{ Freundlich } & $\begin{array}{c}k_{F} \\
\left(\mathrm{mg} \cdot \mathrm{g}^{-1}\left(\mathrm{ppm}^{-1}\right)^{n}\right)\end{array}$ & 3.26 & 4.81 & 9.43 & 8.47 & 6.98 & 30.7 & 31.6 & 28.9 \\
\hline & $n$ & 2.28 & 2.68 & 4.36 & 4.16 & 2.75 & 5.52 & 5.69 & 5.49 \\
\hline & $R^{2}$ & 0.84 & 0.99 & 0.94 & 0.95 & 0.96 & 0.91 & 0.97 & 0.98 \\
\hline \multirow{3}{*}{ Langmuir } & $q_{m}\left(\mathrm{mg} \cdot \mathrm{g}^{-1}\right)$ & - & 57.4 & 40.4 & 36.7 & 75.7 & 74.5 & 61.9 & 74.1 \\
\hline & $k\left((\mathrm{~L} \cdot \mathrm{mg})^{-1}\right)$ & - & 0.01 & 0.04 & 0.04 & 0.01 & 0.43 & 1.23 & 0.19 \\
\hline & $R^{2}$ & - & 0.96 & 0.99 & 0.99 & 0.99 & 0.99 & 0.98 & 0.97 \\
\hline \multirow{4}{*}{ Sips } & $q_{m}\left(\mathrm{mg} \cdot \mathrm{g}^{-1}\right)$ & 45.5 & - & 39.5 & 36.92 & 80.82 & 77.35 & 73.33 & 100.6 \\
\hline & $b\left(\mathrm{~L} \cdot \mathrm{mg}^{-1}\right)$ & 0.01 & - & 0.04 & 0.04 & 0.01 & 0.37 & 0.59 & 0.07 \\
\hline & $n$ & 0.45 & - & 0.96 & 1.02 & 1.13 & 1.24 & 1.89 & 2.56 \\
\hline & $R^{2}$ & 0.97 & - & 0.99 & 0.99 & 0.99 & 0.99 & 0.99 & 0.99 \\
\hline
\end{tabular}

The Scatchard plots obtained for all the materials and both antibiotics are shown in Figure 10. From these plots, the $R^{2}$ and binding constant $\left(k_{d}\right)$ values can be obtained. The first could be related to the presence of nonspecific or multitype interactions, while the second indicates the adsorbate affinity 
for the adsorption sites. The $R^{2}$ values obtained for the TC adsorption on four materials were 0.04 , $0.78,0.99$, and 0.94 for the NC, Si-PILC 25, 50, and 75, respectively. These values suggest that the nonspecific interactions in the adsorption of TC on pillared clays are considerably higher than for the NC. Similarly, the $k_{d}$ values obtained were $0.001,0.02,0.04$, and 0.03 for the NC, Si-PILC 25, 50, and 75, respectively. These values evidence a poor affinity of the $\mathrm{TCH}^{-}$species for the adsorption sites in the four materials; the lowest affinity was obtained for the NC. In the case of CPX adsorption the values obtained were $0.91,0.97,0.93$, and $0.74\left(R^{2}\right)$ and $0.015,0.45,1.36$, and $3.07\left(k_{d}\right)$ for NC, Si-PILC 25, 50, and 75, respectively. As it can be observed, the presence of multitype interactions is lower for this molecule than for the TC and the $k_{d}$ values obtained are higher than those obtained for adsorption of TC on all the materials. This could be due to the lower molecular size of CPX favors the interaction with the pillar for the PILC materials.
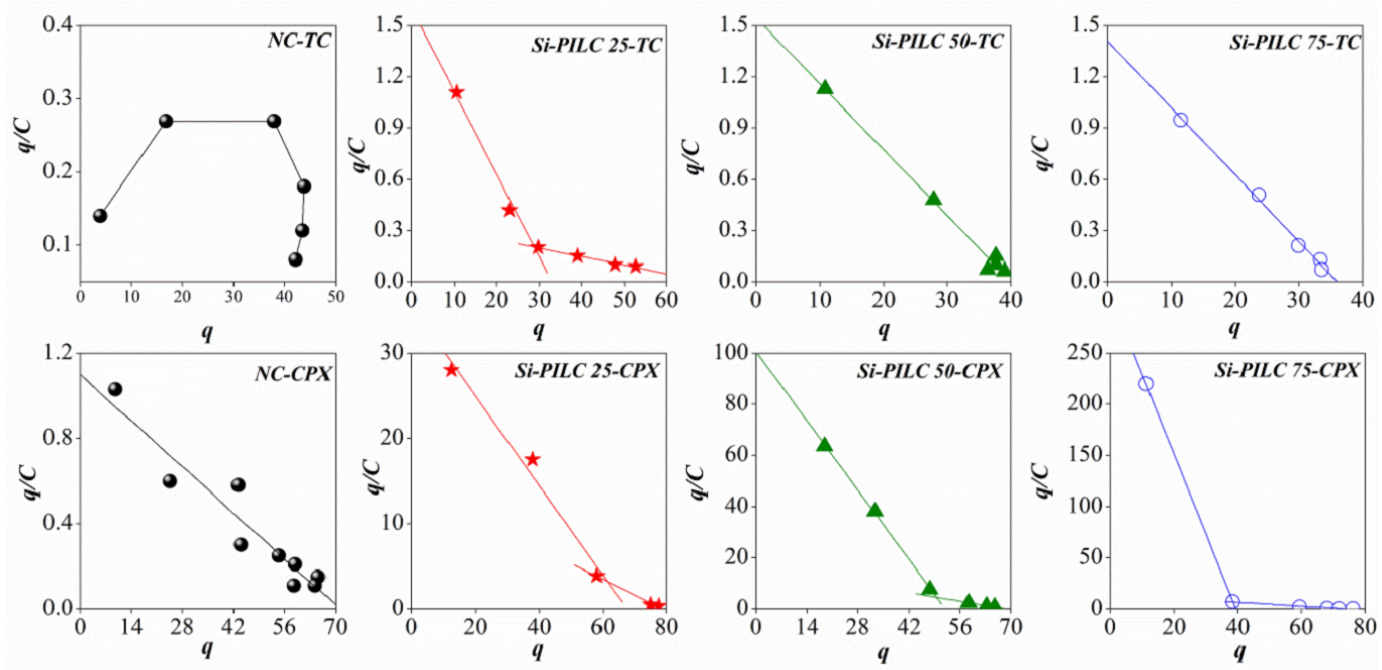

Figure 10. Scatchard plots derived for adsorption data obtained for two antibiotics and the four materials.

Additionally, the Scatchard plot shapes can be related to different adsorption mechanisms. Two different types of plots were obtained for the CPX adsorption, a straight line for the NC and concave curves for the three pillared clays. The first one suggests that there is one type of site for CPX adsorption on the adsorbent surface, whereas the curves acquired for the pillared clays are related to a negative cooperative phenomenon. This last is proposed when two independent sets of data that individually arrange in a linear combination are obtained. Each of them could be associated to two types of affinities of CPX to the surface, one being the consequence of a strong interaction like the formation of inner sphere complexes (high affinity sites) and the other resulting from low affinity interactions like the hydrophobic effect, van der Waals interactions, or hydrogen bridges [25,34,35]. On other hand, Scatchard plots obtained for TC adsorption showed three different shapes. The plot shown for NC resulted in a convex curve suggesting a positive cooperative phenomenon, similar to that proposed for its adsorption isotherms [34,35]. Scatchard plots obtained for the pillared clays showed that Si-PILC 25 has a different behavior than other materials. The plot obtained for $\mathrm{TCH}^{-}$ adsorption on Si-PILC 25 showed a similar behavior that the obtained for the $\mathrm{CPX}^{-}$on pillared clays, where a negative cooperative phenomenon was proposed as the result of the presence of two different adsorption sites for the adsorbate. However, for Si-PILC 50 and 75, straight lines were obtained suggesting that the adsorption of $\mathrm{TCH}^{-}$on these materials occurs in the same type of sites. This last could be due to the fact that TC species only has access to one type of adsorption site because the porous structure denies it access to another one. All the results obtained suggest that the adsorption capacity of Si-PILC depends on their porous structure and the adsorbate molecular sizes. 


\section{Conclusions}

In this study, three silica pillared clays were synthetized, characterized, and evaluated as possible adsorbents of antibiotics from alkaline aqueous media. Adsorption data evidenced a strong relationship among the pillared clays' adsorption capacity, their porous structures, and the antibiotics' molecular sizes. The highest adsorption capacities obtained for CPX on Si-PILC are probably due to the fact that its lower molecular size favors access to the pillars adsorption sites. TC adsorption data on silica pillared clays evidenced that for this molecule the porous structure limits the interaction between the $\mathrm{TCH}^{-}$and the pillars. The adsorption results for both antibiotics suggested that the negative species interact with different adsorption sites on the pillared structure. Finally, the mechanism proposed for the adsorption of anionic species on Si-PILC could be considered as negative cooperative phenomena.

Author Contributions: M.E.R.J. designed and performed the experiments, analyzed the data, and wrote the paper. F.T., M.B., and K.S. cooperated with the data analysis and manuscript elaboration. All the authors read and approved the final manuscript.

Funding: This research was received no external funding.

Acknowledgments: The authors gratefully acknowledge the Universidad Nacional del Comahue, Universidad Nacional San Luis, PROBIEN (CONICET-UNCo), INFAP (CONICET-UNSL), and ANPCyT (Agencia Nacional de Promoción Científica y Tecnológica) for their financial support.

Conflicts of Interest: The authors declare no conflicts of interest.

\section{References}

1. Dietrich, D.R.; Hitzfeld, B.C.; O'Brien, E. Toxicology and Risk assessment of pharmaceuticals. In Organic Pollutants in the Water Cycle; Reemtsma, T., Jekel, M., Eds.; John Wiley \& Sons: Weinheim, Germany, 2006; pp. 287-309.

2. Homem, V.; Santos, L. Degradation and removal methods of antibiotics from aqueous matrices-A review. J. Environ. Manag. 2011, 92, 2304-2347. [CrossRef] [PubMed]

3. Grassi, M.; Kaykioglu, G.; Belgiorno, V.; Lofrano, G. Removal of Emerging contaminants from water and wastewater by adsorption process. In Emerging Compounds Removal from Wastewater: Natural and Solar Based Treatments; Lofrano, G., Ed.; Springer: Dordrecht, The Netherlands, 2012; pp. 15-37.

4. Van Doorslaer, X.; Dewulf, J.; Van Langenhove, H.; Demeestere, K. Fluoroquinolone antibiotics: An emerging class of environmental micropollutants. Sci. Total Environ. 2014, 500, 250-269. [CrossRef] [PubMed]

5. Akhtar, J.; Amin, N.A.S.; Shahzad, K. A review on removal of pharmaceuticals from water by adsorption. Desalin. Water Treat. 2016, 57, 12842-12860. [CrossRef]

6. Rakić, V.; Rac, V.; Krmar, M.; Otman, O.; Auroux, A. The adsorption of pharmaceutically active compounds from aqueous solutions onto activated carbons. J. Hazard Mater. 2015, 282, 141-149.

7. Balarak, D.; Mostafapour, F.K.; Bazrafshan, E.; Saleh, T.A. Studies on the adsorption of amoxicillin on multi-wall carbon nanotubes. Water Sci. Technol. 2017, 75, 1599-1606. [CrossRef] [PubMed]

8. Liang, Z.; Zhaob, Z.; Sun, T.; Shi, W.; Cui, F. Adsorption of quinolone antibiotics in spherical mesoporous silica: Effects of the retained template and its alkyl chain length. J. Hazard Mater. 2016, 305, 8-14. [CrossRef] [PubMed]

9. Calisto, V.; Ferreira, C.I.; Oliveira, J.A.; Otero, M.; Esteves, V.I. Adsorptive removal of pharmaceuticals from water by commercial and waste-based carbons. J. Environ. Manag. 2015, 152, 83-90. [CrossRef] [PubMed]

10. Chen, H.; Gao, B.; Li, H. Removal of sulfamethoxazole and ciprofloxacin from aqueous solutions by graphene oxide. J. Hazard Mater. 2015, 282, 201-207. [CrossRef] [PubMed]

11. Mabrouki, H.; Akretche, D.E. Diclofenac potassium removal from water by adsorption on natural and Pillared Clay. Desalin. Water. Treat. 2016, 57, 6033-6043. [CrossRef]

12. Wu, H.; Xie, H.; He, G.; Guan, Y.; Zhang, Y. Effects of the $\mathrm{pH}$ and anions on the adsorption of tetracycline on iron-montmorillonite. Appl. Clay Sci. 2016, 119, 161-169. [CrossRef]

13. Al-Khalisy, R.S.; Al-Haidary, A.M.A.; Al-Dujaili, A.H. Aqueous phase adsorption of cephalexin onto bentonite and activated carbon. Sep. Sci. Technol. 2010, 45, 1286-1294. [CrossRef]

14. Genç, N.; Dogan, E.C.; Yurtsever, M. Bentonite for ciprofloxacin removal from aqueous solution. Water Sci. Technol. 2013, 68, 848-855. [CrossRef] 
15. Jiang, W.-T.; Chang, P.-H.; Wang, Y.-S.; Tsai, Y.; Jean, J.-S.; Li, Z.; Krukowski, K. Removal of ciprofloxacin from water by birnessite. J. Hazard Mater. 2013, 250-251, 362-369. [CrossRef] [PubMed]

16. Roca Jalil, M.E.; Baschini, M.; Sapag, K. Influence of $\mathrm{pH}$ and antibiotic solubility on the removal of ciprofloxacin from aqueous media using montmorillonite. Appl. Clay Sci. 2015, 114, 69-76. [CrossRef]

17. Gil, A.; Korili, S.A.; Vicente, M.A. Recent Advances in the control and characterization of the porous structure of pillared clay catalysts. Catal. Rev. 2008, 50, 153-221. [CrossRef]

18. Gil, A.; Assis, F.C.C.; Albeniz, S.; Korili, S.A. Removal of dyes from wastewaters by adsorption on Pillared clays. Chem. Eng. J. 2011, 168, 1032-1040. [CrossRef]

19. Hou, M.-F.; Ma, C.-X.; Zhang, W.-D.; Tang, X.-Y.; Fan, Y.-N.; Wan, H.-F. Removal of rhodamine B using iron-pillared bentonite. J. Hazard Mater. 2011, 186, 1118-1123. [CrossRef] [PubMed]

20. Liu, Y.N.; Dong, C.; Wei, H.; Yuan, W.; Li, K. Adsorption of levofloxacin onto an iron-pillared montmorillonite (clay mineral): Kinetics, equilibrium and mechanism. Appl. Clay Sci. 2015, 118, 301-307. [CrossRef]

21. Mishra, T.; Mahato, D.K. A comparative study on enhanced arsenic (V) and arsenic (III) removal by iron oxide and manganese oxide pillared clays from ground water. J. Environ. Chem. Eng. 2016, 4, 1224-1230. [CrossRef]

22. Molu, Z.B.; Yurdakoç, K. Preparation and characterization of aluminum Pillared K10 and KSF for adsorption of thimethoprim. Micropor. Mesopor. Mat. 2010, 127, 50-60. [CrossRef]

23. Roca Jalil, M.E.; Baschini, M.; Rodríguez-Castellón, E.; Infantes-Molina, E.; Sapag, K. Effect of the Al/clay ratio on the thiabendazole removal by aluminum pillared clays. Appl. Clay Sci. 2014, 87, 245-263. [CrossRef]

24. Roca Jalil, M.E.; Vieria, R.S.; Azevedo, D.; Baschini, M.; Sapag, M. Improvement in the adsorption of thiabendazole by using aluminum pillared clays. Appl. Clay Sci. 2013, 71, 55-63. [CrossRef]

25. Roca Jalil, M.E.; Baschini, M.; Sapag, K. Removal of Ciprofloxacin from Aqueous Solutions Using Pillared Clays. Materials 2017, 10, 1345. [CrossRef] [PubMed]

26. Han, Y.S.; Matsumoto, H.; Yamanaka, S. Preparation of new silica sol-based Pillared clays with high Surface area and high thermal stability. Chem. Mater. 1997, 9, 2013-2018. [CrossRef]

27. Rouquerol, F.; Rouquerol, J.; Sing, K.; Llewellyn, P.; Maurin, G. Adsorption by Powders and Porous Solids: Principles Methodology and Applications, 2nd ed.; Elsevier: Amsterdam, The Netherlands, 2013.

28. Villarroel-Rocha, J.; Barrera, D.; García Blanco, A.A.; Roca Jalil, M.E.; Sapag, K. Importance of the $\alpha$-plot Method in the characterization of nanoporous materials. Adsorpt. Sci. Technol. 2013, 31, 165-183. [CrossRef]

29. Del Piero, S.; Melchior, A.; Polese, P.; Portanova, R.; Tolazzi, M. A novel multipurpose Excel tool for equilibrium speciation based on newton-raphson method and on a hybrid genetic algorithm. Ann. Chim. 2006, 96, 29-49. [CrossRef] [PubMed]

30. Bodo, A.; Ciavardini, A.; Giardini, A.; Paladini, A.; Piccirillo, S.; Scuderi, D. Infrered multiple photon dissociation spectroscopy of ciproflocacin: Investigation of the protonation site. Chem. Phys. 2012, 398, 124-128. [CrossRef]

31. Chopra, I.; Hawkey, P.M.; Hinton, M. Tetracyclines molecular and clinical aspects. J. Antimicrob. Chemoth. 1992, 29, 245-277. [CrossRef]

32. Ho, Y.S.; McKay, G. A comparison of chemisorption kinetic models applied to pollutant removal on various sorbents. Process Saf. Environ. Protect. 1998, 76, 332-340. [CrossRef]

33. Wu, F.C.; Tseng, R.L.; Juang, R.S. Initial behavior of intraparticle diffusion model used in the description of adsorption kinetics. Chem. Eng. J. 2009, 153, 1-8. [CrossRef]

34. Febrianto, J.; Kosasih, A.N.; Sunarso, J.; Ju, Y.; Indraswati, N.; Ismadji, S. Equilibrium and kinetic studies in adsorption of heavy metals using biosorbent: A summary of recent studies. J. Hazard Mater. 2009, 162, 616-645. [CrossRef] [PubMed]

35. Gezici, O.; Kara, H.; Ayar, A.; Topkafa, M. Sorption behavior of $\mathrm{Cu}(\mathrm{II})$ ions on insolubilized humic acid under acidic conditions: An application of Scatchard plot analysis in evaluating the $\mathrm{pH}$ dependence of specific and nonspecific bindings. Sep. Purif. Technol. 2007, 55, 132-139. [CrossRef]

36. Dahlquist, F.W. The Meaning of Scatchard and Hill Plots. In Methods of Enzymology; Hirs, C.H.W., Timasheff, S.N., Eds.; Academic Press: New York, NY, USA, 1978; Volume 48, pp. 270-299.

37. Komadel, P.; Madejová, J. Acid activation of Clay Minerals. In Handbook of Clay Science Developments in Clay Science, Part, A: Fundamentals, 2nd ed.; Bergaya, F.G., Lagaly, G., Eds.; Elsevier Ltd.: Amsterdam, The Netherlands, 2013; Volume 2, pp. 385-408. 
38. Mendioroz, S.; Pajares, A.; Benito, I.; Pesquera, C.; González, F.; Blanco, C. Texture evolution of montmotillonite under progressive acid treatment: Change from $\mathrm{H}_{3}$ to $\mathrm{H}_{2}$ type of hysteresis. Langmuir 1987, 3, 676-681. [CrossRef]

39. Madejová, J. FTIR techniques in clay mineral Studies. Vib. Spectrosc. 2003, 31, 1-10. [CrossRef]

40. Thommes, M.; Kaneko, K.; Neimark, A.V.; Olivier, J.P.; Rodriguez-Reinoso, F.; Rouquerol, J.; Sing, K.S. Physisorption of gases, with special reference to the evaluation of surface area and pore size distribution (IUPAC Technical Report). Pure Appl. Chem. 2015, 87, 1051-1069. [CrossRef]

41. Parolo, M.E.; Avena, M.J.; Savini, M.C.; Baschini, M.T.; Nicotra, V. Adsorption and circular dichroism of tetracycline on sodium and calcium-montmorillonites. Colloid Surf. A 2013, 417, 57-64. [CrossRef]

42. Chang, P.H.; Li, Z.; Jiang, W.T.; Jean, J.S. Adsorption and intercalation of tetracycline by swelling clay minerals. Appl. Clay Sci. 2009, 46, 27-36. [CrossRef]

43. Parolo, M.E.; Savini, M.C.; Vallés, J.M.; Baschini, M.T.; Avena, M.J. Tetracycline adsorption on montmorillonite: $\mathrm{pH}$ and ionic strength effects. Appl. Clay Sci. 2008, 40, 179-186. [CrossRef]

44. Marco-Brown, J.L.; Barbosa-Lema, C.M.; Torres Sanchez, R.M.; Mercader, R.C.; dos Santos Afonso, M. Adsorption of picloram herbicide on iron oxide pillared montmorillonite. Appl. Clay Sci. 2012, 58, $25-33$. [CrossRef]

45. Azizian, S. Kinetic models of sorption: A theoretical analysis. J. Colloid Interface Sci. 2004, 276, 47-52. [CrossRef] [PubMed]

46. Giles, C.H.; Smith, D.; Huitson, A. A general treatment and classification of the solute adsorption isotherm. I. Theoretical. J. Colloid Interf. Sci. 1974, 47, 755-765. [CrossRef]

47. Limousin, G.; Gaudet, J.P.; Charlet, L.; Szenknect, S.; Barthes, V.; Krimissa, M. Sorption isotherms: A review on physical bases, modeling and measurement. Appl. Geochem. 2007, 22, 249-275. [CrossRef]

(C) 2018 by the authors. Licensee MDPI, Basel, Switzerland. This article is an open access article distributed under the terms and conditions of the Creative Commons Attribution (CC BY) license (http:/ / creativecommons.org/licenses/by/4.0/). 